\title{
Infertility-Related Risk Factors: A Systematic Review
}

\author{
Narjes Deyhoul ${ }^{1}$, Tina Mohamaddoost ${ }^{1}$, Meimanat Hosseini ${ }^{2}$
}

\begin{abstract}
Objectives: Infertility is a universal barrier affecting people all over the world and its cause and importance may vary according to the geographical location and socio-economic condition. Infertility Awareness is the first step in maintaining pregnancy power in lifestyle modification.

Materials and Methods: Some studies were conducted on some databases such as PubMed, Scopus, Springer and Science Direct. Twenty-five English papers with similar subject as ours published from 2010 to 2015 were reviewed.

Results: Reproductive system disorders, the symptoms of sexually transmitted diseases and hormonal disorders are among the infertility causes in men and women. Lifestyle-related factors such as obesity, nutrition, smoking and alcohol consumption, mobile phone use, sexual violence and anxiety were evaluated as pregnancy changers.

Conclusion: Having a healthy lifestyle, running regular tests and checkups under medical supervision and maintaining normal body weight can prevent from fertility problems. Infertility in women will be treated by medicine, minor surgery, laparoscopic procedures, and hormone therapy and by avoiding early pregnancy failure. This article is useful and beneficial for all medical and scientific researchers who want to uproot infertility.

Keywords: Infertility-related risk factors, Infertility symptoms, Infertility causes
\end{abstract}

\section{Introduction}

Oxford English Dictionary defines the word "infertile" or barren as "inability to give birth or procreate." This definition refers to the "sterilization mode rather than visualization difficulty" and presents so many clinical perspectives (1). According to the reports of the International Committee for Monitoring Assisted Reproductive Technology (ICMART) and the World Health Organization (WHO), "infertility" is a couple's failure in pregnancy after 12 months of unprotected sexual intercourse and pregnancy attempts. Infertility is a global problem affecting people around the world whose cause and importance may vary according to the geographical location and socio-economic condition. According to the statistics, annually 60-80 million couples around the world suffer from infertility (2). The estimated fertility rate in Canada is $11.5 \%$ to $15.7 \%$. One out of seven English couples suffers from fertility problems (3). The number of couples affected by infertility has increased from 42.0 million people $(39.6$ million people, 44.8 million people) in 1990 to 48.5 million people ( 45.0 million people, 52.6 million people) in 2010 (4). Ten to $12 \%$ of couples around the world are suffering from infertility in half of which, the man is infertile. The estimates show that in $35 \%-40 \%$ of cases, the man is infertile and in $35 \%-40 \%$ of cases, the woman is infertile and in $20 \%-30 \%$ of cases, it is related to the combination of other factors (5). Infertility occurs once pregnancies are ended up with abortion (ASR) or the delivery of a child with multiple hereditary diseases (6). Infertility diagno- sis is different and may include the evaluation of sperm quality; Mormons, and analysis of imaging of uterus and fallopian tubes. According to the medical diagnosis, infertility may be treated by reproductive surgery, prescribing hormones or applying infertility technologies (2). Infertility awareness, like men and women's awareness of risk factors, is the first step in protecting pregnancy in lifestyle modification. Knowledge and awareness of fertility depends on education rather than personal fertility or motherhood and fatherhood experience. Health improving strategies started with educational interventions (3). Secondary infertility refers to a state in which pregnancy does not occur after one year (in some epidemiologic studies 2 years) of unprotected sexual intercourse despite at least one pregnancy in the past. Women with secondary infertility cannot give birth to alive child (7). Infertility may result from a wide range of abnormalities one or both of which exist. However, infertility is not much different in people and it can have a variety of causes (8). The primary and secondary causes of infertility are reviewed in this study. This study examines the following points: primary causes of infertility, such as genetic factors, hormonal disorders, genetic disorders, congenital defects or reproductive system diseases; secondary factors, including lifestyle related factors, such as obesity, diet, smoking, alcohol consumption and chemical environments, and secondary factors related to human infertility such as unsafe methods of childbirth and post-partum period as well as symptoms of sexually transmitted diseases. 


\section{Materials and Methods}

This study reviews the articles on infertility related risk factors. This research mainly aims to find risk factors that cause infertility. The infertility factors related to primary and secondary infertility are discussed in the main results of the published scientific papers. There were some studies conducted on database of PubMed, Scopus, Springer, Science Direct and thirty English articles with similar subject as ours were found in 2010-2015. Twenty-five articles were also evaluated.

\section{Results}

Some major factors of infertility include the impact of the reproductive system disorders, reproductive system diseases, hormonal disorders, age, alcohol consumption, and smoking, immune response, cell phone use, sexual violence, stress, obesity, nutrition, and any chronic disease reducing the chance of successful pregnancy and unknown factors.

Table 1 shows some articles with their study type, year of publication, authors, and their main findings on the infertility related risk factors.

\section{The impact of the reproductive system disorders}

A review of articles shows that female infertility may be clue to solve ovulation problems, anatomical problems, such as fallopian tube damage or endometriosis (3). In womb, congenital disorders, muscle tissue gland, endometriosis, polyps and adhesions can also reduce fertility (8). The reasons for male infertility include unusual characteristics of semen, reproductive infection and disorder, erectile dysfunction or ejaculation disorder. After testing and treating each etiologic factor, couples may look for assisted reproductive technology (3).

\section{Endometriosis}

Endometriosis is a benign estrogen-dependent inflammatory disease which develops due to the ectopic endometrial implants. Endometriosis affects more than 10\%-15\% of women who are of childbearing age (3). The relationship between endometriosis and infertility has been mentioned in many resources. However, a cause and effect relationship is still controversial. The pelvic anatomy is deformed and fertility is decreased through mechanical adhesion, such as pelvic adhesion. These adhesions cause damage to ovule release or selection, decrease sperm motility, and causing disruption in myometrium contraction, such as fertilization disorder and embryo transfer. Infertile women are more likely to develop the disease. However, so much debate has been raised on the impact of diseases on fertility. Anti-genetic growth factors, inflammatory cytokines and normal genes are among the endometriosis-related etiologic factors of infertility (9).

The impact of Genital Infections and Diseases Untreated sexually transmitted infections (STIs) are among the factors that cause damage to the reproductive system of men and women. Chlamydia and gonorrhea are most common STI which lead to infertility in men and women. Chlamydia is among the most common STI in England and 196 new cases affected with this infection were identified in 2011; youth (aged 15-24) were at risk of this disease more than others. This disease has no symptom. Thus, it cannot be diagnosed and treated. Chlamydia causes problems for men and women. If chlamydia is left untreated, the woman will be also at risk of pelvic inflammatory disease (PID). PID is a serious condition where the upper part of the female reproductive system and its supporting structures become inflamed (10). The studies show that pre-pregnancy diagnosis of Chlamydia trachomatis reduces the abortion caused by PID in 4 weeks. Valid evidence also shows that women with PID are at risk of ectopic pregnancy, fallopian tube infertility and chronic pelvic pain (11). Among the 14551 reasons or required treatment for IVF mentioned in 2010, most of them are related to fallopian tube. A relationship was observed between infertility and previous Chlamydia infection in women (12). There is so much evidence indicating the relationship between trachomatis infection and any changes in semen quality. Trachoma can affect the sperm function. In vitro experiments show that $C$. trachomatis Tyrosine phosphorylation affects sperm proteins, causes sperm premature death and develops an apoptosis-like reaction in sperms which increase sperm surface fragmentation levels (13).

\section{The Impact of Age}

Studies show that the risk of infertility increases with growing age (3). Young people's knowledge of infertility is hopeful and leads to the maintenance and improvement of pregnancy health (12). Evidence shows that age may play an important role in fertility. Pregnancy before 30 for women and before 35 for men has more chance of success. Men and women should know each other's ages that they could come to an agreement for a successful pregnancy (14).

\section{The Impact of Hormonal Disorders}

There are many hormonal disorders that cause infertility. Hypothyroidism, hyperprolactinemia (high male hormone levels) and luteal phase defect (low progesterone) are a few examples of these disorders. Hormonal disorders are a major cause of infertility in women. The inability of women at ovulation and regulation of hormone levels leads to too high or too low production of hormones. These hormonal disorders are characterized with symptoms such as irregular menstrual cycles, excessive bleeding, or very little bleeding, pelvic and abdominal cramps, absence of menstruation or long menstruation and excessive weight loss or weight gain. The following factors may cause hormonal disorders: gland problems such as thyroid gland, pituitary gland and hypothalamus gland problems. These preliminary glands are responsible for the production of sex hormones. Birth control pills, stress and some diseases such as hypothyroidism affect these glands. If any of these glands encounter any problem, a 
Table 1. Summery and Details of the Articles

\begin{tabular}{|c|c|c|c|}
\hline No. & Year & Authors & Main Results \\
\hline 1 & 2015 & Jaiswal et al. & $\begin{array}{l}\text { Apoptosis is an essential process including a wide range of physiological and pathological measures. In this study, functional } \\
\text { polymorphism in the cell death pathway genes FASLG was genotype to review its role in male infertility. }\end{array}$ \\
\hline 2 & 2015 & Jensen et al. & $\begin{array}{l}\text { The men using saturated fat in their diet have a pathological life. These men have a lower BMI. BMI is not always related to fat } \\
\text { mass, and the men using saturated fat may have a lower BMI due to their lower muscle mass. This lifestyle and demographic } \\
\text { factors can affect semen quality. }\end{array}$ \\
\hline 3 & 2014 & $\begin{array}{l}\text { Seshadri and } \\
\text { Sunkara }\end{array}$ & $\begin{array}{l}\text { Meta-analysis studies have shown a difference of the number of peripheral NK cells in fertile and infertile women with RM in } \\
\text { response to the fertility controls presented at higher levels of peripheral NK cells in fertile and infertile women with RM. }\end{array}$ \\
\hline 4 & 2014 & $\begin{array}{l}\text { Meneses and } \\
\text { Holland }\end{array}$ & $\begin{array}{l}\text { Young women who are still of childbearing age include } 6 \% \text { of breast cancer patients and their age-related requests for treatment } \\
\text { and pregnancy protection are noteworthy. } \\
5 \text { of bariatric surgery on the number and quality of eggs in patients who have experienced assisted reproductive technology }\end{array}$ \\
\hline 5 & 2014 & $\begin{array}{l}\text { Christofani } \\
\text { et al }\end{array}$ & $\begin{array}{l}\text { Fertility in women who underwent bariatric surgery increased compared with those who controlled obesity; especially those } \\
\text { recognized by PCOS. Weight loss can reduce the symptoms of androgen and insulin resistance. }\end{array}$ \\
\hline 6 & 2014 & Sheehan et al & $\begin{array}{l}\text { The pathophysiological mechanisms relating varicocele to infertility must be fully understood. All men with varicoceles are not } \\
\text { infertile. It means that molecular and genetic factors can contribute to finding the pathogenesis of varicocele infertility. }\end{array}$ \\
\hline 7 & 2014 & Pastore et al & $\begin{array}{l}\text { Nearly } 10 \% \text { of infertile/sub-fertile women are recognized with DOR....percent of whom will be automatically fertilized. Women } \\
\text { with DOR, regardless of age, are less successful in assisted reproductive technology. }\end{array}$ \\
\hline 8 & 2014 & Li et al & $\begin{array}{l}\text { Fallopian tube damage caused by surgery, fallopian tube infections and diseases, or previous EP may lead to higher EP in women } \\
\text { who underwent IVF treatment. The increased risk of EP in IVF women may be related to fallopian tube infertility or surgical }\end{array}$ \\
\hline
\end{tabular}
procedure rather than IVF.

2013 Goundry et Youth have little information and knowledge about STI and infertility problem; they do not have full understanding in this regard. Youth have little information and knowledge about STI and infertility problem; they do not have full understanding in this regard.
Sexual health education should start at an early age and focus on how untreated STI may cause infertility. The impact of Smoking on the progress of many diseases has been proven, and experts have published it in special publications. In this study, smoking affected the analysis of the patient's sperm change, and the results were statistically significant.

Since the undergraduate students of University of Ottawa regarded infertility as a biomedical health issue, reproductive inactivity.

2013 Sabarre et al

In this study, women and men regarded infertility as a biomedical problem and could identify several risk factors for male and female infertility.

Cook and Different endometriosis diagnosis tests, scoring systems, and medical data results have recently been published. EFI has presented a basis for predicting pregnancy rate in 3 years and provided a simple visual graph for training the doctor and the
prifferent endom patient.

132013 Tsai et al

Women with PCOS have a higher BMI and a larger waist. Diet and energy and macronutrient distribution can contribute to high $\mathrm{BMI}$ of women with PCOS.

Schistosoma is one of the main causes of low fertility in endemic areas, and the primary diagnosis and treatment with praziquantel can treat infer
Schistosoma haematobium.
Women who suffer from secor Women who suffer from secondary infertility are more like housewives who used inappropriate approaches for delivery and post-natal and menstrual care. They used household vaginal washes which are a risk factor for secondary infertility. Secondary infertility risk factors include unsafe procedures during childbirth, post-partum and menstruation.

2012 Macer and It is clear how rare diseases can cause infertility. These disorders cause damage to the ovule release and selection, decrease sperm motility, and causing disruption in myometrium contraction, such as removing fertilization and embryo transfer. The disease is likely to progress in infertile women. $172012 \begin{aligned} & \text { Palihawadana } \\ & \text { et al }\end{aligned}$ Ovulation morbidity and impaired sex relationship are among the regular findings in the infertile. There were a few women with pelvic injury and Bilateral tubal obstruction.

Obesity makes it difficult to do prenatal care, such as anatomic scans, estimation of fetal weight and hearing of fetus heartbeat. A fat body's physiology makes the pregnancy difficult for women, such as lower back pain. Metabolic disorder refers to central obesity focused syndrome and insulin resistance, and is a subclinical inflammation function.

202011 Tang et al

The decision to perform genetic test or consultation is influenced by pervious infertility experiences, medical symptoms, and acceptance of genetic synthesizer for their infertility in many infertile couples.

Immunological mechanisms contribute to vaginal problems, including RM, infertility and implantation failure. Therefore, successful pregnancy depends on maternal compliance of immune response to the growing semi-allogeneic fetus. NK cells are a part of the innate immune system which is found in the peripheral blood and endometrium.

Prenatal and maternal care along with prevention and better management of HIV/STI will prevent from infertility. In addition,

212011 Dhont et al the reduction of dead child labor and neonatal mortality rate and Improvement of access to family planning plays an important role; especially for young mothers.

$22 \quad 2011$ Ashok et al Mobile equipment and communication devices emit electromagnetic radio frequency waves which decrease sperm quality and normal functioning of the body. The testicles exposure to these waves can have a negative effect on Spermatozoon.

232011 Hickman and The risk of SLE and its treatment are effective and important in infertility. In some patients, lupus symptoms progressed after one or more child labors, and in a significant proportion of patients, the disease was progressed prior to child birth.

242010 Akande et al Typically, women realize the infection after several years being at risk of it. Therefore, the tests which only discover the existence of micro-organisms can be used to detect the pervious risk of $\mathrm{C}$. trachomatis. In the case-control study of infertile women, serology determined the previous size of Chlamydia.

252010 Dhont et al

History of sexual violence, HIV and HSV-2 infection affect infertility of Rwanda women; especially infertility of fallopian tube factor. HIV and HSV-2 infection are the most important risk factor for infertility in men.

Abbreviations: BMI, body mass index; PCOS, polycystic ovary syndrome; NK, natural killer; RM, recurrent miscarriage; EFI, Endometriosis Fertility Index; STI, sexually transmitted infection; EP, ectopic pregnancy; IVF, in vitro fertilization; DOR, diminished ovarian reserve. 
disorder can prevent from the full process of ovulation, and thereby, pregnancy will become difficult. In addition, some treatments can cause hormonal disorders. Targeted cancer therapies can cause anatomical and hormonal changes which negatively affect the breast cancer patient's sexual potential. There are large differences in the evidence-based interdisciplinary treatment and management of breast cancer young patients who are treated and are fertile now and there are concerns about pregnancy after cancer treatment (15).

The Impact of Smoking and Alcohol Consumption Meta-analyzes have shown that $40 \%$ of infertile men are smokers (3). Chemicals (such as nicotine, cyanide and carbon monoxide) in cigarettes cause a rapid destruction of ovules. Unfortunately, ovules cannot be replaced if destroyed. It means that female smokers experience menopause one to four years sooner. The number and quality of sperm decrease in male smokers; sperm mobility is reduced and the number of sperms with abnormal appearance increases. Smoking may make the sperm unable to fertilize eggs (16). Female smokers do not get pregnant like non-smoking women. Infertility rate in male and female smokers is almost double the infertility rate in non-smoking women. The reproductive risk increases with the daily number of cigarettes. Even fertility treatments such as in vitro fertilization (IVF) may not be able to completely eliminate the effects of smoking on fertility. During IVF, female smokers need more drugs to stimulate ovulation and have fewer ovules. Female smokers have 30\% lower chance of pregnancy through IVF method compared to non-smoking women (15). Alcohol consumption in men reduces sperm count; and motility and number of normal morphology sperm in them (3).

\section{The Impact of Immune Responses}

Immunological mechanism plays an important role in sexual problems, such as recurrent miscarriage (RM) (three or more RSA), infertility and implantation failure. This shows that successful pregnancy depends on the maternal immune response to the growing semi-allogeneic fetus (17). Embryo implantation is affected by local and systemic immune responses including immunoglobulins, cytokines, and hormonal and endometrial factors. Contribution of these factors to the success of implantation and pregnancy is critical. Natural killer cells play an important role in female sexual function. This cells are correlated with inductive failures, NK cell cytotoxicity induced abortion or infertility and gene expression (18).

The Impact of Mobile Phone Use

Mobile device emits radio frequency electromagnetic waves that can reduce sperm quality and disrupt the normal function of the body. There are many real mechanisms emphasizing the impact of mobile phones on sexual ability of men. All these mechanisms rely on the impact of mobile phones on biological system, such as thermal and non-thermal effects. Since testicles are a shallow organ, it may absorb the radiant energy more than other organs. Oxidative stress (OS) developed in testicles because cell phones cause free radicals in sperm. OS is a major cause of infertility in men (19).

\section{The Impact of Sexual Violence}

The literature shows that the history of sexual violence is associated with infertility. The psychological trauma caused by sexual violence leads to ovulation infertility or sexual dysfunction. Infertile women had experienced sexual violence three times in their lives compared to fertile women. Although the relationship between sexual violence and fallopian tube infertility could be easily explained, this relationship with any infertility other than fallopian tube infertility is vague and confusing. This may be due to the fact that fallopian tube pathology was diagnosed using human chorionic gonadotropin (HSG) against laparoscopy as a gold standard method. HSG is an unreliable test for tube openness with an intensity of $62 \%$ and sensitivity of $83 \%$. Therefore, non-tubal infertility group includes an unknown number of undetectable tubal infertility (20).

\section{The Impact of Anxiety}

Although the impact of anxiety on male infertility has not been clearly proved, the incidence of such problems in the lives of men may cause anxiety. Once faced with their infertility, men may have excessive stress, including the anxiety related to power, masculinity, and sexual adequacy. The anxiety may decrease the intimacy between partners and avoid the sexual behavior (21).

\section{The Impact of Obesity}

According to the researchers, obese women, especially women with abdominal fat hardly become pregnant and have low chance of infertility treatment. In women with a body mass index $(\mathrm{BMI})>25$, compared with $\mathrm{BMI}<25$, the pregnancy rate is lower (respectively, $10.5 \%$ vs. $253 \%$ ). The correlation between obesity and polycystic ovary syndrome (PCOS) contributes to the infertility in obese women (22). PCOS is an androgen excess mode with insulin resistance which makes pregnancy difficult. The role of obesity in pregnancy focuses on the physiology of fat body and metabolic disorders (16). Articles show that nearly $10 \%$ of sub-fertile or infertile women have been diagnosed with diminished reduced ovarian (DOR) (23). Polycystic ovary is one of the common reasons of ovulation disorder in women of childbearing age (24). Some studies have shown that usually $30 \%-70 \%$ of women with PCOS are obese. Overweight and obesity in women with PCOS exacerbates the severity of androgen and disorders metabolic profile (25).

The impact of Diseases That Can Cause Infertility Systemic lupus erythematosus (SLE) is a multiple automatic system that affects fertility in women and men. Genital tract in women and men may be affected by cytotoxic treatment due to the disease activity. Fertility disorder 
may be due to the problems which prevent from successful fertilization and thus lead to infertility, avoid the effective implantation in the uterine wall and cause problems in maintaining pregnancy after implantation and complications during childbirth (26). Varicocele is a pathological enlargement of the pampiniform venous plexus in the scrotum that affects testicular function and can lead to infertility. However, the pathophysiological mechanism that leads to varicocele infertility is not fully understood. The following five mechanisms seem to contribute to the impact of varicocele on testicular function, reduced blood flow leading to hypoxia, thermal stress, oxidative stress, hormonal imbalance and detoxification (27).

\section{The Impact of Nutrition}

Although no definitive relationship was discovered, selection of supplements or food groups is crucial before and during pregnancy attempt to improve fertility in women and men (28). A high saturated fat diet is associated with reduced sperm quality. Changes in diet over the last decades may partly explain the high frequency of abnormal sperm count. Decrease in saturated fat intake in general and reproductive health benefit (29). Lower sperm concentration and total sperm count are correlated in men with saturated fat diet (3).

\section{Unknown Factors}

There are numerous factors affecting infertility and nature has multiple roles in this fact. The special impact of some of these factors on fertility is still uncertain and unclear. The relationship of these factors with fertility in humans remains unclear and further research is required in this regard (14).

\section{Discussion}

As reported by the WHO, reproductive health is influenced by several environmental factors which intervene and interfere in the organism and its function or psychological nature (30). Due to the multiple roles of the nature of these factors, such as a variety of factors affecting fertility, these factors and their relationships will be measured and controlled; it is difficult to reduce fertility. The transparent relationship between this factor and parameters makes it difficult to evaluate fertility. That is why the specific impact of these factors on fertility is still unclear. That is because the special impact of these factors on fertility is still unclear and their relationship with human fertility is still unclear and further research is required in this regard (14).

Lifestyle factors, such as early start age in the family, nutrition, weight management, exercise, mental stress, smoking, use of prescribed drugs and self-medications without prescription, use of alcohol and caffeine, occupational and environmental risks, preventive care, and other behaviors are modifiable and may affect fertility (31). Overweight or very low weight men and women are in danger of negative side effects including changes in hormone levels which affect their fertility. Recent studies suggest that weight has a significant role in fertility. That is, weight control and maintenance is an ideal way for couples to increase fertility. Exercise is also very important. However, excessive exercise is harmful. Lean and low weight men and women who do so much exercise may be at risk of sub-fertility. So, weight balance is the best chance of achieving pregnancy (29).

This article tries to explain the different perspectives that lead to infertility. Thus, we have reviewed many articles. In general, each article discusses a relevant factor and this study has gathered all the significant factors. Through these articles, researchers obtain a wide insight about infertility factors.

\section{Conclusion}

Female infertility may occur in the form of lack of ovulation, blocked fallopian tubes, endometriosis or uterine abnormalities. Male infertility factor is morphologically determined by reducing the production of motile and normal sperm. Genetic abnormalities, hormonal imbalances, and congenital genital abnormalities and infections are among the common reasons for infertility in women and men. Lifestyle factors such as obesity, diet, smoking and alcohol consumption along with exposure to environmental chemicals have been studied as infertility modifiers. In general, women should be properly trained and have enough knowledge of safe exercise during pregnancy and childbirth. Endurance in health lifestyle, regular checkups and normal weight should avoid infertility problems. Female infertility can be definitely treated by medicine, minor surgery, laparoscopy meters, hormone therapy and prevention from early pregnancy failure. Such reviews are conducted by all medical and scientific researchers trying to end infertility.

\section{Ethical Issues}

Not applicable.

\section{Conflict of Interests}

The authors declare no conflict of interests.

\section{Financial Support}

The authors received no financial support or grant from any funding agency.

\section{References}

1. Gurunath S, Pandian Z, Anderson RA, Bhattacharya S. Defining infertility: a systematic review of prevalence studies. Hum Reprod Update. 2011;17(5):575-588. doi:10.1093/humupd/dmr015.

2. Sudha G, Reddy KS. Causes of female infertility: a crosssectional study. International Journal of Latest Research in Science and Technology. 2013;2(6):119-123.

3. Sabarre KA, Khan Z, Whitten AN, Remes O, Phillips KP. A qualitative study of Ottawa university students' awareness, knowledge and perceptions of infertility, infertility risk factors and assisted reproductive technologies (ART). Reprod Health J. 2013;10(41):1-10. doi:10.1186/1742-4755$10-41$ 
4. Mascarenhas MN, Flaxman SR, Boerma T, Vanderpoel $\mathrm{S}$, Stevens GA. National, regional, and global trends in infertility prevalence since 1990: a systematic analysis of 277 health surveys. Plos Med. 2012;9(12):e1001356. doi:10.1371/journal.pmed.1001356.g005

5. Scarneciu I, Lupu S, Scarneciu C. Smoking as a risk factor for the development of erectile dysfunction and infertility in men; evaluation depending on the anxiety levels of these patients. Soc Behav Sci. 2014;127(1):437-442. doi:10.1016/j. sbspro.2014.03.286.

6. Cozaru GC, Butnariu LI, Gorduza EV. Genetic counselling in reproductive disorders. Soc Behav Sci. 2012;33(1):213217. doi:10.1016/j.sbspro.2012.01.114.

7. Dhont N, Luchters S, Muvunyi C, et al. The risk factor profile of women with secondary infertility: an unmatched case-control study in Kigali, Rwanda. BMC Womens Health. 2011;11:32. doi:10.1186/1472-6874-11-32.

8. Palihawadana TS, Wijesinghe PS, Seneviratne HR. Aetiology of infertility among females seeking treatment at a tertiary care hospital in Sri Lanka. Ceylon Med J. 2012;57(2):79-83. doi:10.4038/cmj.v57i2.4461.

9. Macer ML, Taylor HS. Endometriosis and infertility: a review of the pathogenesis and treatment of endometriosisassociated infertility. Obstet Gynecol Clin North Am. 2012;39(4):535-549. doi:10.1016/j.ogc.2012.10.002.

10. Goundry RAL, Finlay ER, Liewellyn CD. Talking about links between sexually transmitted infections and infertility with college and university students from SE England, UK: a qualitative study. Reprod Health. 2013;10(47):1-7. doi:10.1186/1742-4755-10-47.

11. Akande V, Turner C, Horner P, Horne A, Pacey A. Impact of Chlamydia trachomatis in the reproductive setting: British fertility society guidelines for practice. Hum Fertil. 2010;13(3):1-18. doi:10.3109/14647273.2010.513893.

12. Li C, Meng CX, Zhao WH, Lu HQ, Shi W, Zhang J. Risk factors for ectopic pregnancy in women with planned pregnancy: a case-control study. Eur J Obstet Gynecol Reprod Biol. 2014;181:176-182. doi:10.1186/s12884-0150613-1.

13. Adisa J, Egbujo EM, Yahaya BA, Echejoh G. Primary infertility associated with schitosoma mansoni: a case report from the Jos plateau, north central Nigeria. Afr Health Sci. 2012;12(4):563-565. doi:10.4314/ahs.v12i4.26.

14. Sarvari A, Heidari M, et al. Effect of environmental risk factors on human fertility. J Reprod Infertil. 2010;11(4):211225.

15. Meneses K, Holland AC. Current evidence supporting fertility and pregnancy among young survivors of breast cancer. Continuing Nursing Education. 2014;43(3):374381. doi:10.1111/1552-6909.12301

16. Jaiswal D, Trivedi S, Agrawal NK, Singh K. Association of polymorphism in cell death pathway gene FASLG with human male infertility. Asian Pacific Journal of Reproduction. 2015;4(2):112-115.

17. Tang A, Alfirevic Z, Quenby S. Natural killer cells and pregnancy outcomes in women with recurrent miscarriage and infertility: a systemic review. Hum Reprod.
2011;26(8):1971-1980. doi:10.1093/humrep/der164.

18. Seshadri S, Sunkara S. Natural killer cells in female infertility and recurrent miscarriage: a systematic review and meta-analysis. Hum Reprod Update. 2014;20(3):429438. doi:10.1093/humupd/dmt056.

19. Ashok A, Aspinder S, Alaa H, Kavindra K. Cell phones and male infertility: a review of recent innovations in technology and consequences. Int Braz J Urol. 2011;37(4):432-454.

20. Dhont N, Wijgert JV, Luchters S, Muvunyi C, Vyankandondera J, Temmerman M. Sexual violence, HSV-2 and HIV are important predictors for infertility in Rwanda. Hum Reprod. 2010;25(10):2507-2515. doi:10.1093/ humrep/deq189.

21. Cook AS, Adamson GD. The Role of Endometriosis Fertility Index (EFI) and endometriosis scoring systems in predicting infertility outcomes. Curr Obstet Gynecol Reprod. 2013;2(1):186-194. doi:10.1007/s13669-0130051-x.

22. Nodine PM, Hastings-Tolsma M. Maternal obesity: improving pregnancy outcomes. MCN Am J Matern Child Nurs. 2012;37(2):110-115.

23. Pastore LM, Karns LB, Ventura K, Clark ML. Longitudinal interviews of couples diagnosed with diminished ovarian reserve undergoing fragile X permutation testing. J Genet Couns. 2014;23(1):97-107. doi:10.1007/s10897-013-9616-0.

24. Tsai YH, Wang TW, Wei HJ, et al. Dietary intake, glucose metabolism and sex hormones in women with polycystic ovary syndrome (PCOS) compared with women with nonPCOS-related infertility. Br J Nutr. 2013;109(1):2190-2198. doi:10.1017/S0007114512004369.

25. Christofani J, Bianco B, Santos G, Adami F. Bariatric surgery influences the number and quality of oocytes in patients submitted to assisted reproduction techniques. Obesity. 2014;22(3):939-942. doi:10.1002/oby.20590.

26. Hickman RA, Gordon C. Causes and management of infertility in systemic lupus erythematosus. Rheumatology. 2011;50(9):1551-1558. doi:10.1093/rheumatology/ker105.

27. Sheehan MM, Ramasamy R, Lamb DL. Molecular mechanisms involved in varicocele-associated infertility. J Assist Reprod Genet. 2014;31(5):521-526.

28. Clementi M, Tiboni GM, Causin R, et al. Pesticides and fertility: an epidemiological study in Northeast Italy and review of the literature. Reprod Toxicol. 2008;26(1):13-18. doi:10.1016/j.reprotox.2008.05.062.

29. Jensen T, Heitmann BL, Blomberg JM, Halldorsson T, Andersson AM. High dietary intake of saturated fat is associated with reduced semen quality among 701 young Danish men from the general population. Am J Clin Nutr. 2013;97(1):411-418. doi:10.3945/ajcn.112.042432.

30. Negro-Vilar A. Stress and other environmental factors affecting fertility in men and women: overview. Environ Health Perspect Suppl. 1993;101(2):59-64.

31. Sami N, Saeed AT, Wasim S, Saleem S. Risk factors for secondary infertility among women in Karachi, Pakistan. PLoS One. 2012;7(4):e35828. doi:10.1371/journal. pone. 0035828

Copyright (C) 2017 The Author(s); This is an open-access article distributed under the terms of the Creative Commons Attribution License (http://creativecommons.org/licenses/by/4.0), which permits unrestricted use, distribution, and reproduction in any medium, provided the original work is properly cited. 